\title{
The introduction of new technologies in the development and production of roads
}

\author{
E.M. Akhmetshin ${ }^{1}$, and K.E. Kovalenko ${ }^{2 *}$ \\ ${ }^{1}$ Kazan Federal University, Elabuga Institute of KFU, Elabuga, Russian Federation \\ ${ }^{2}$ Altai State University, Barnaul, Russian Federation
}

\begin{abstract}
In connection with modern economic conditions, great attention is paid to the use of new materials and modern technologies. According to the results of the analysis of technical characteristics, materials are used to ensure the economic effect of the initial cost of construction and reduce costs during operation. Experts and scientists agree that the use of innovative materials becomes economically viable at the stage of construction and subsequent operation of the road surface. It is new technologies that are designed to improve road safety in our country of costly repairs. In this case, areas with permafrost soils and regions with difficult climatic conditions, which are characterized by seasonal freezing of soils, deserve special attention.
\end{abstract}

\section{Introduction}

Road organizations carry out high-quality re-equipment of enterprises with construction equipment and machinery. This allows you to increase the volume of construction work, reduce construction time, improve quality.

Today, contractors are armed with modern excavators, powerful bulldozers, tandem vibratory compactor rollers of various weights, multi-ton dump trucks and other equipment for the transportation of building materials, both domestic and imported.

Since 2007 the use of macadam-mastic asphalt has begun to cover roads, which has gained high popularity as a wear-resistant pavement material on roads with a high degree of congestion, providing steady and increased flatness, roughness, cracking resistance and adhesion during operation, reduces noise level from moving vehicles.

Since 2012, polymer-bitumen binder 60 has been used as a binder in the composition of macadamic-mastic asphalt concrete at the construction and reconstruction of roads, which improves the performance properties of asphalt concrete and extends the service life of the coating.

Since 2014, the NOVACHIP technology has been successfully applied, consisting in the installation of thin-layer coatings (wear layer) of a hot bitumen-mineral mixture using a special paver for pre-applied bitumen-latex cationic emulsion. This technology allows to increase the turnaround time of repair of the road and improve the quality of the coating (evenness, noise absorption, coupling qualities).

\footnotetext{
* Corresponding author: publisher88@ mail.ru
} 
At the same time, there are no disadvantages inherent in traditional surface treatment such as the ejection of crushed stone, limiting the speed of movement, uniformity of the coating, and so on.

Also started using warm asphalt mixes. To warm asphalt mixes classify mixtures with a laying temperature of $90-120^{\circ} \mathrm{C}$. The advantages of these mixtures are laying and compaction at low air temperatures, and hence the extension of the construction season, increasing the distance of transportation of asphalt concrete mixtures.

The road workers use cold asphalt mixes. Since 2012, such mixtures have been widely used in patching roads. Also found use when performing patching repair reused milled asphalt. Technologies and construction materials associated with the use of man-made waste have become popular.

There is a shortage of crushed granite, the main supplier of which is Ukraine. In order to reduce the number of deliveries of this material from abroad, technologies are being worked out and tests of soils reinforced with innovative materials are being carried out, which will make it possible to obtain travel clothing that is equivalent to the design using traditional materials, that is, sand and rubble.

At the device of asphalt concrete pavements, modern imported pavers are used in combination with a mounted non-contact ultrasonic leveling system, which can significantly improve the evenness of the surface of the asphalt concrete being laid.

There is a re-equipment in the production of asphalt mixes - modern asphalt production plants are being acquired and installed, which is under the control of computer programs.

Overhaul of the roads did not stand aside either. Contractors have mechanisms such as recyclers and road mills, which are used to overhaul road surfaces.

These mechanisms make it possible to remove a worn layer of asphalt concrete, recycle it and after adding a new material together with structuring additives, re-lay it in the base of the coating, and then lay the asphalt concrete coating. This technology allows you to enhance the carrying capacity of the pavement, extend the turnaround time, and most importantly, in a short time to produce significant amounts of work.

\section{Methods}

The current research uses the methods of observation, comparative legal studies, formal logic, description and interpretation. When developing documentation at the design stage, the application of new high-tech processes is envisaged. These include the use of 3D control systems for road construction equipment in the construction of road bed, the preparation of pavement bases and coatings.

In the technical design assignment for design institutes, it is mandatory to create a digital model of a section of a highway, according to which the working bodies of roadbuilding equipment are controlled. When performing road works, this technology allows to reduce the level of negative influence of the "human factor", improve accuracy and shorten the time frame for the execution of the design solution.

\section{Results}

In order to optimize the cost of construction and installation work and reduce the time of construction of bridges in 2012, the production of reinforced concrete beams of superstructures that meet the highest requirements of bridge inspection to the quality of products, length from 11.9 to 28, was organized on the basis of Belgorod LLC. Advanced design, which allows to reduce the number of beams in the span without reducing the load capacity and reliability. Previously, reinforced concrete beams had to be purchased at 
factories of reinforced concrete products located in the Rostov, Leningrad or Moscow regions. Due to the high cost of objects with the use of reinforced concrete and metal beams of superstructures, in 2012-2014, pedestrian overpasses were implemented, which is made of wood-glued timber. From 2013, galvanized steel railings are used. Such a solution can significantly reduce maintenance costs and extend the life of the building envelope.

Considering that the service life of bridge structures directly depends on the type of waterproofing material and the quality of its application, since 2011, a modified bitumenlatex emulsion has been used to waterproof the span structures of bridge structures. The advantage over traditional waterproofing materials is sprayed method of its application. After solidification, a strong and uniform structure is formed, providing a higher quality of waterproofing in hard-to-reach places. This method is the least time consuming and has great performance [1-2].

The next step in the application of innovative materials and modern technologies in the industry will be the introduction of composite materials, that is, materials based on fiberglass, basalt fibers and so on. The advantage of such materials compared to metal is in higher strength and low lightness, as well as resistance to aggressive media.

Consider some modern road construction technologies.

1. The Superpave System (Top Performance Asphalt Pavement) is the latest product of the Strategic Highway Research Program (SHRP) (Fig. 1).

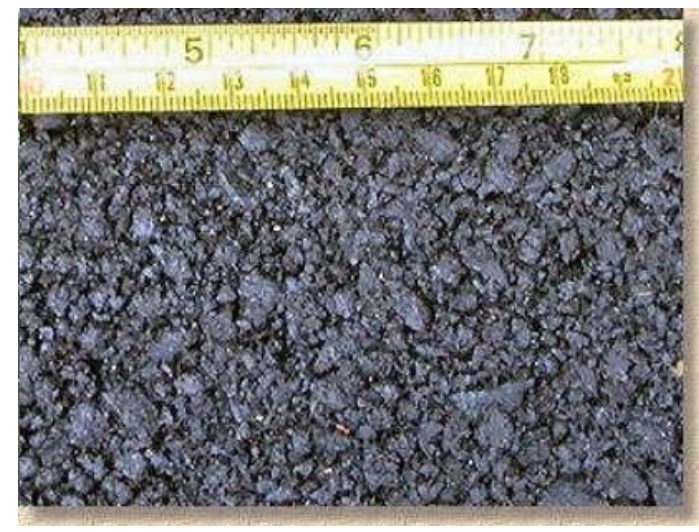

Fig. 1. The Superpave System

The Superpave system is:

- a comprehensive system for designing mixtures that meet the highest requirements for performance, depending on the traffic load, climatic and structural conditions at a particular installation site. Improving the performance of the coating is achieved by designing and combining the most suitable bituminous binder, mineral component and, if required, the modifier;

- a kit that combines over 25 SHRP products into a single system for the design and analysis of mixtures. The Super pave system combines specifications for new materials, test methods, methods for designing mixtures into a single integrated coordinated package;

- the Superpave system was developed to replace the separate technical conditions and design methods for mixtures used in 50 states of the USA, and now it is a single system applicable to specific climatic conditions and traffic loads on any stretch of road surface in the United States and Canada;

- The super pave system is applicable for fresh and recycled dense, hot asphalt concrete mixes (GUS), with or without modifiers, for laying new coatings, as well as for surface layers. The system is designed to minimize residual deformation, fatigue cracking, low- 
temperature cracking, it allows to evaluate the effect of aging and moisture on the development of the above three coating defects.

\section{COLD RESIKLING}

Usually there are several options for restoring a damaged road, and it is often difficult to determine which one is the best. However, the answer to two important questions is intended to help determine which of the options is optimal according to the "cost / effectiveness" criterion.

A quick inspection to visually assess the condition of the road in combination with some basic tests (for example, measuring deviations) is usually sufficient to assess the mechanism of destruction. It is important to determine whether damage is limited by the closing layer (or top layers of the pavement) or the pavement structure is damaged.

For example, a 15-year estimated lifespan of the road planned, or less capital expenditures are envisaged, only to maintain the existing rate of deterioration and maintain the required quality of pavement for a further, say, five years? These question have one single goal: to determine the most cost-effective solution to a specific problem within the framework of the project requirements.

Surface recovery. Surface restoration is limited to the upper layers of the pavement to a depth of $100 \mathrm{~mm}$. Damage here is usually associated with the aging of bitumen and cracking, which starts from the surface under the influence of heat [3-4].

Laying a thin (about $40 \mathrm{~mm}$ ) layer of hot asphalt concrete over the damaged surface. This is the easiest way to superficial restore. Modified binders are often used to make asphalt concrete to increase the service life of the closing layer. However, repeated deposition of a layer of wear, on top of the existing one, increases the height of the roadway and can create problems with the passage through it and drainage.

Grinding of the damaged layer and its replacement. When using this method, the damaged layer of asphalt concrete is removed and replaced with a layer of new hot asphalt concrete mixture, often with a modified binder. This method is relatively fast due to the high performance of modern milling machines. Destructions are removed together with a layer of asphalt concrete, and the height of the road is preserved. But at the same time there are costs for the transportation and disposal of the removed layer.

Recycling with the addition of bitumen emulsion to the material of the existing pavement (recycling at a shallow depth). A new, cold material is made from the crushed material of old clothes in the regenerator-mixer at the place of work. This type of recycling is intended to introduce a fresh bitumen emulsion into existing asphalt concrete. In addition, the quality of the final asphalt mix was purposefully changed by the addition of an emulsion.

Strengthening pavement. Elimination of damage to the pavement is usually made as a long-term solution. Compaction of granulated material is actually an improvement, since the higher the density of the material, the better its strength characteristics.

- Complete reconstruction. This is an option when restoration is combined with reconstruction. In essence, the reconstruction implies the construction of a new road. Where traffic flows are large, it is sometimes more appropriate to build a new road along a separate highway.

- Applying additional layers (of granular material and / or of asphalt concrete) over the existing surface. Thick, stacked layers of asphalt concrete are often the simplest solution to problems with pavement under heavy loads. However, increasing the height of the road often requires a separate drainage device and creates problems with road traffic.

- Recycling to a greater depth, to the entire depth of damaged pavement, thus creating a new thick homogeneous layer with higher strength characteristics. Additional layers can be laid over the recycled layer where the pavement needs to be substantially upgraded. Stabilizers are added to the recycled material (bitumen emulsion, if necessary, high-strength 
crushed stone), especially where the material of the existing pavement is of insufficient quality and needs to be strengthened. The task of recycling is to maximize the recovery of existing pavement. In addition to using the material of the upper layers of the existing pavement again, the material below the recycling level remains intact.

3. Cold Recycling Method. Constantly increasing traffic intensity on public roads, as well as increasing the axle loads twice, requires an increase in the carrying capacity of the pavement of existing roads.

Currently, in the field of road construction, along with the traditional methods of repair, reconstruction and strengthening of highways, fundamentally new technologies have appeared that meet the latest requirements of the ever increasing traffic intensity, based on the latest achievements of science and technology.

One of such technologies that most fully meets the requirements for reconstruction, repair and conditions of operation of roads is the "Cold recovery method" (recycling).

This method of repairing coatings is a modern, well-proven method for road organizations, and is unique in that it provides for the restoration of the foundation of pavement by a method that allows reuse of the material of the old coating. The use of this method allows to reduce the time of reconstruction, repair, significantly reduce costs. Work by the method of cold regeneration is carried out without stopping the movement.

The method of cold regeneration (recycling) is a strengthening (stabilization) of soils, stone materials and asphalt granulate with astringent materials by preliminary milling and mixing on the road. This achieves significant material savings. In addition, the destruction of the old coating allows you to eliminate the source of the appearance of new reflected cracks. No recycling of the old coating is required [5-9].

When carrying out works on regeneration, a special mechanism is used: the regenerator-mixer RM-350B of the American company CATERPILLAR with a capacity of up to $1.6 \mathrm{~km}$ of a seven-meter road per shift. Which can perform all types of regeneration. The scheme of the working body of the regenerator-mixer RM-350B.

\section{Cold Recycling Application}

When restoring damaged pavements, the most cost-effective repair methods turn out to be methods that take into account specific conditions, which is less typical in the construction of new roads. Each project is unique in relation to the structure of the existing pavement and the quality of its materials and the roadbed. Therefore, it is very important to choose the technology that best meets the conditions of this particular work area. The following factors should be taken into account:

Location and the choice of the most effective solution for a given country or region is influenced by the conditions of the local environment: such as traffic on a city street requiring repair, the ability to perform work not only at night but also during the day, the carrying capacity of a dirt road that requires urgent repairs, etc. Already in these two cases, completely different solutions and road maintenance requirements are required. It is also important to know the local standards for road construction, as well as the attitude of the local population to the quality of the roads, which they regard as acceptable.

Physical environment. When selecting the optimal recycling method, topological and geological conditions should be taken into account. Very steep inclines may require recycling as much as possible in practice. Fluctuations in climatic conditions are most important when choosing the best recycling technology: for regions with low rainfall, completely different technologies are needed compared to regions where this level is high. The results of exposure to extreme temperatures, such as cracking caused by meltingfreezing cycles, should also be taken into account when choosing the necessary technology.

Availability of materials. The availability of the necessary materials, especially stabilizers, significantly affects the feasibility of various recycling options. They must be available in sufficient quantities and have the required quality. Modern Recycler require a 
large number of stabilizers, so from the very beginning it must be determined whether they can be supplied.

Kinds of cold recycling:

- Deep recycling.

Recycling to a greater depth covers a wide range of applications of this technology: to enhance damaged pavements in order to extend their service life by an appropriate time. The subsequent application of the locking layers on top of the recycled layer improves the performance properties of the restored road, such as skid resistance, etc. The typical recycling depth here exceeds $150 \mathrm{~mm}$.

Recycling to a greater depth can be used to strengthen damaged pavements with thick and thin asphalt concrete layers.

Immediately after recycling, a new locking layer is needed. For low-loaded roads, this may be a layer of rubble or a thin layer of hot asphalt concrete mix. Where the pavement must be subjected to high loads, it may be necessary to lay asphalt concrete layers as well as an asphalt concrete wear layer.

- Shallow depth recycling.

Shallow depth recycling is usually performed to eliminate significant cracking of asphalt concrete layers and to improve their performance. This type of recycling is often undertaken for the construction of roads with a short lifespan, but can also be used where the pavement is "healthy" and only the upper asphalt concrete layers are weakened. Recycling in this case is usually performed to a depth of 80 to $150 \mathrm{~mm}$.

Using shallow depth recycling, the pavement design can be improved by laying a closing asphalt concrete layer. By reducing the penetration of water into the main layers, the life of the pavement is increased.

\section{- Reconstruction of dirt roads.}

The reconstruction of dirt gravel roads by strengthening them with an organic binder can be accomplished by treating their gravel with a bitumen emulsion followed by a thin crushed stone or other protective layer [10-16]. The advantages of this method are the absence of dust from traffic in a dry time and safer driving conditions in rainy weather, with less likelihood of loss of stability of vehicles. In addition, mineral resources are much better used because there is no need for regular replacement of gravel (for dirt roads, the annual loss of 20 to $30 \mathrm{~mm}$ of gravel due to traffic and weather conditions is common). This reduces the environmental damage caused by the constant need to open all new quarries and quarries for gravel mining. The depth of recycling of this type is usually from 100 to $150 \mathrm{~mm}$.

It is important to note that it is also possible to strengthen gravel roads by adding cement to their material. But then a thicker recycled layer, about $200 \mathrm{~mm}$, is needed. As a result, this case should be attributed rather to recycling to a greater depth (Table 1).

Table 1. Comparative analysis of methods for the reconstruction of the roadway

\begin{tabular}{|c|c|c|}
\hline & Methods & Signs \\
\hline \multirow[t]{7}{*}{1.} & \multirow{7}{*}{$\begin{array}{l}\text { The list of } \\
\text { necessary work } \\
\text { carried out with } \\
\text { traditional methods } \\
\text { of reconstruction: }\end{array}$} & The device bypass (backup) road; \\
\hline & & $\begin{array}{l}\text { Dismantling the design of the roadway bulldozers, } \\
\text { excavators; }\end{array}$ \\
\hline & & $\begin{array}{l}\text { Removal of materials received from disassembly and their } \\
\text { disposal; }\end{array}$ \\
\hline & & Creating a longitudinal profile; \\
\hline & & $\begin{array}{l}\text { Stabilization (compaction) of the road base with rollers } \\
\text { impregnated with bitumen compositions; }\end{array}$ \\
\hline & & The device sandy foundation of the road; \\
\hline & & The device of macadam base - 3 layers (fractions) with \\
\hline
\end{tabular}




\begin{tabular}{|c|c|c|}
\hline & & compaction of each layer by rollers; \\
\hline & & Subcoating with bitumen compositions; \\
\hline & & The device of asphalt concrete pavement (by calculation); \\
\hline & & $\begin{array}{l}\text { The device curbs by adding soil with layer-by-layer } \\
\text { compaction; }\end{array}$ \\
\hline & & $\begin{array}{l}\text { The device covering the roadsides of rubble impregnated } \\
\text { with bitumen compositions. }\end{array}$ \\
\hline 2. & The list of & Dry loosening at the calculated depth; \\
\hline & necessary work & Road grading by motor graders; \\
\hline & $\begin{array}{l}\text { carried out when } \\
\text { using the method of }\end{array}$ & $\begin{array}{l}\text { Laying high-strength granite rubble on the road surface (if } \\
\text { necessary, strengthen the base); }\end{array}$ \\
\hline & cold regeneration: & $\begin{array}{l}\text { Loosening at the calculated depth with injection of bitumen } \\
\text { emulsion; }\end{array}$ \\
\hline & & Re-profiling of the roadway by motor graders; \\
\hline & & Compaction; \\
\hline & & The device of asphalt concrete pavement (by calculation); \\
\hline & & Extension of the shoulders if necessary. \\
\hline
\end{tabular}

Based on this analysis, it can be seen that the use of the cold regeneration method allows to exclude a number of operations from the technological process. There is no need to set up a bypass road, eliminating the work associated with the dismantling of the roadway, removal and disposal of the materials received [8]. The device of the sand and crushed-stone bases is not required, since during regeneration, the existing base is not damaged. Significantly reduced the number involved in the work of equipment.

\section{Conclusions}

The value of introducing innovative technologies in the construction of roads is great. They significantly reduce costs and time to repair roads, increase the service life of roads, provide external compliance time. Modified materials improve the quality of life of people. All innovative technologies are developed taking into account the negative impact of external factors; they become environmentally friendly and safe.

The main task that now stands in the way of the development of the road industry is to create conditions under which the construction of high-quality roads with long maintenance-free life will be beneficial for all. Of course, in this matter, the rejection of outdated materials and the transition to a new stage of development, which is characterized by the use of innovative technologies and solutions, is of particular importance. Contrary to sustainable opinion, innovations in construction can be economically viable. After all, new materials significantly extend the life of the roadway, eliminating the regions from the need for frequent repairs.

Experts and scientists agree that the use of innovative materials becomes economically viable at the stage of construction and subsequent operation of the road surface. It is new technologies that are designed to improve road safety in our country of costly repairs. In this case, areas with permafrost soils and regions with difficult climatic conditions, which are characterized by seasonal freezing of soils, deserve special attention.

\section{References}

1. B.A. Lyovin, Innovatics in scientific ensuring transport safety. The World of Transport, 1 (2012) 
2. R.M.A. Albertin, E. Moraes, Neto G. Angelis, B.L.D. Angelis, E. Coverloni, F.F.S. Silva. Diagnóstico da gestão dos resíduos sólidos urbanos do município de Flórida Paraná. Revista Agro@mbiente On-line, 4 (2017)

3. L.A. Nagashima, Junior C. Barros, C.C. Andrade, E.T. Silva, C. Hoshika. Gestão integrada de resíduos sólidos urbanos - uma proposta para o município de Paranavaí, Estado do Paraná, Brasil. Acta Scientiarum. Technology, Maringá, 33 (2015)

4. V. Owusu, J. M. Boaherg, C. Sundberg. Journal of Environmental Studies and Sciences, 1 (2015)

5. H.Ali, N.Ali, A.R.Ahmad, M. Ibrahim, S. Ahmad, S. Yaacob. Advances in natural and applied sciences, 6 (2017)

6. Kovalenko K.E. Middle East Journal of Scientific Research. 16. 6 (2013)

7. A.Durán Moreno, G. M.arcés Rodríguez, A.R. Velasco, Marín J.C. Enriquez, R. Gutiérrez Lara. Características y análisis de composición de los residuos sólidos de la Ciudad de México. Rev. Int. Contam. Ambient, México, 29 (2015)

8. T.V. Zyuba, Industrial safety in transport. Tutorial (Academy of Civil Aviation, SPb, 2004)

9. An.B. Mottaeva, As.B. Mottaeva, Economy and entrepreneurship, 3-2 (56-2) (2015)

10. URL :

https://www.revistas.unijui.edu.br/index.php/desenvolvimentoemquestao/article/view/ 2903 (access on: 15 Jun. 2018)

11. S.I. Girko, A.V. Gubareva, K.E. Kovalenko. Revista Conrado, 13. 60 (2017)

12. V. F. Nascimento, A. C. Sobral, P. R. Andrade. Evolução e desafios no gerenciamento dos resíduos sólidos urbanos no Brasil. Rev. Ambient. Água, Taubaté, 10 (2018)

13. B.I. Kochurov. Geography of ecological situations (eco-diagnostics of territories). (Moscow, IG RAS, 2014)

14. A.V. Tabakova. Humanities and Education, 3 (2016)

15. T. Eshet, O.Ayalon \& M. Shechter. Resources, Conservation and Recycling, 46 (2016)

16. R.R. Kazaryan, I.A. Bunkina. Natural and technical sciences, 6(84) (2015) 